\section{Students can now practise on virtual patients}

Universal Simulation UK has launched their first affordable medical 'flight simulator', the Model T, which enables students to perform treatments on virtual patients. With the use of haptics (a motorised arm which gives accurate haptic feedback for virtual touch), the simulations make treatments feel like they would with a real patient and can distinguish between soft and hard tissue - without having to put any real patients at risk.

Universal Simulation UK are targeting dental operations to begin with, starting with simulations in restoration and oral surgery. They are also developing a simulation to teach anaesthesia which combines virtual reality (VR) and haptics together in a single simulation.

By bringing a virtual simulation to life with the use of haptics in this way, it improves the training which can be delivered through plastic props. Students are able to

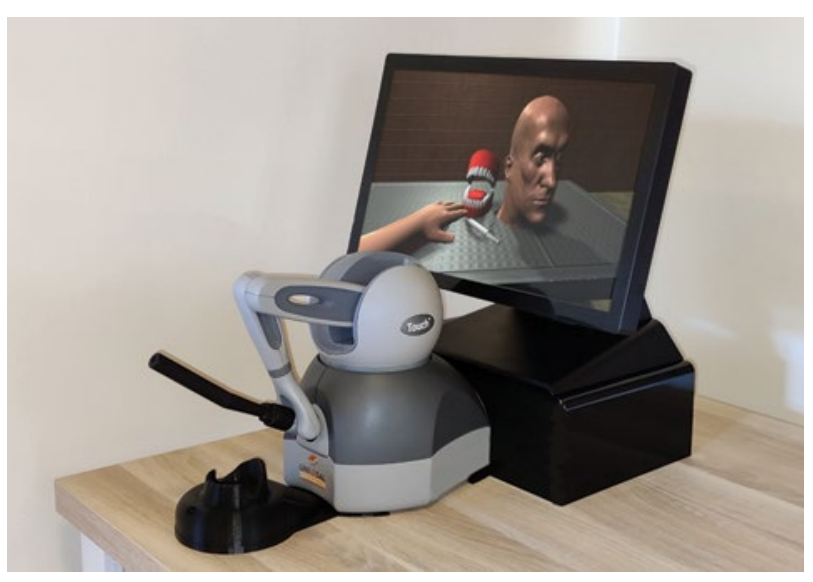

\section{Easily seen, easily cleaned}

The touchscreen display on the Belmont Touch $\mathrm{x}$-ray is easily cleaned, which is particularly beneficial to users in the current climate. Functionality and performance go hand in hand. The compact unit produces instant error code reports and has multi-lingual functionality. It also switches into 'sleep mode' to conserve energy and contains a USB port and handheld exposure switch which can be wall mounted if required. Belmont Touch is also aesthetically appealing and has a zero-drift scissor-arm, which means it can be neatly stowed away against the wall when not in use, making it less intrusive and potentially intimidating for a patient.

Belmont Touch is compatible with any type of digital imaging system. Not only does it reduce the soft x-rays absorbed by the tissues, making it safer and more reassuring for patients, but the tube voltage, current and exposure time can all be selected according to the individual clinical need, helping to avoid unnecessary exposure to radiation.

Offering a minimum exposure time of just 0.01 seconds, the Belmont Touch pre-programmed timer is selectable for digital systems and two different types of films. A total of 16 film speeds are available and the lightweight, compact, easy to hold tube head enables the operator to align the tube accurately every time for reproducible, high contrast, crisp radiographs with excellent image quality.

For further information call 02075150333 or email dental@takara.co.uk.

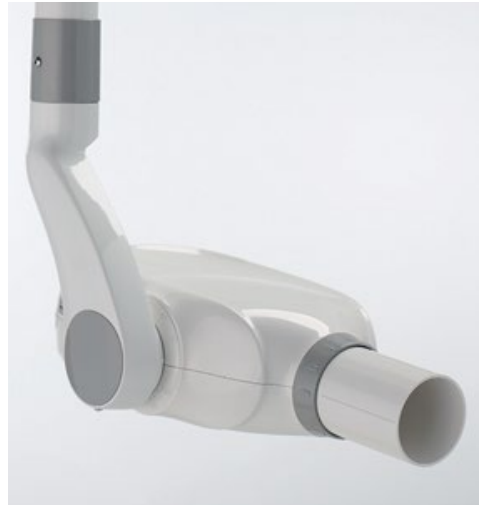

\section{Digital Innovations Forum} this December

Align Technology, Inc. has announced that it will host its first Digital Innovations Forum on 2 and 3 December 2020 from $5 \mathrm{pm}$ to $8 \mathrm{pm}$ (CET). The two-day virtual meeting will be delivered digitally to bring together an international panel of speakers to showcase the latest thinking about practice-related digital innovations. Their collective aim will be to demonstrate how practitioners can adopt improved digital workflows and more efficient treatment experiences - for their practices and ultimately for their patients.

To date, Align has invested over $\$ 1$ billion (US) in research and development of its cutting-edge technology, including Invisalign aligners and iTero intraoral scanners to advance solutions for dental professionals and their patients. The company remains focused on elevating practices beyond their current position in their digitisation and optimisation efforts, assisting in futureproofing the dental profession.

Throughout the Digital Innovations Forum, the roster of speakers will explore why the shift to digital is happening right now, and why embracing digital technology is an essential part of a dynamic business.

Bo Dahlbom, a lecturer on the importance of digitalisation for business and society, IT professor at the University of Gothenburg, chairman of the board of Activation, and a long-time adviser to the government on IT policy issues, will start the plenary session with an insight into 'The Digital Revolution and Dental Care'.

Align Technology has lined up an array of experienced clinicians from around the world who will share their knowledge and experience, and provide easily actionable advice, so practitioners can immediately start applying what they learn.

For more information about the Digital Innovations Forum and to register, visit https:// aligndigitalinnovationsforum.com/. 